\title{
Cost-Effective Electrochemical Activation of Graphitic Carbon Nitride on the Glassy Carbon Electrode Surface for Selective Determination of Serotonin
}

\author{
Vijayaraj Kathiresan ${ }^{1,+}$, Thenmozhi Rajarathinam ${ }^{2,+}$, Seulah Lee ${ }^{3}$, Suhkmann Kim ${ }^{4}$, \\ Jaewon Lee ${ }^{3}$ (D) Dinakaran Thirumalai ${ }^{2, *(\mathbb{D})}$ and Seung-Cheol Chang ${ }^{2, *(D)}$ \\ 1 Graduate Department of Chemical Materials, Pusan National University, Busan 46241, Korea; \\ vijaya.raj6@gmail.com \\ 2 Department of Cogno-Mechatronics Engineering, Department of Optics and Mechatronics Engineering, \\ College of Nanoscience and Nanotechnology, Pusan National University, Busan 46241, Korea; \\ thenmozhi@pusan.ac.kr \\ 3 College of Pharmacy, Pusan National University, Busan 46241, Korea; \\ leeseulah@pusan.ac.kr (S.L.); neuron@pusan.ac.kr (J.L.) \\ 4 Department of Chemistry, Pusan National University, Busan 46241, Korea; suhkmann@pusan.ac.kr \\ * Correspondence: dinakaran@pusan.ac.kr (D.T.); s.c.chang@pusan.ac.kr (S.-C.C.); \\ Tel.: +82-(0)51-510-3729 (D.T.); +82-(0)51-510-2276 (S.-C.C.); Fax: +82-(0)51-514-2358 (D.T. \& S.-C.C.) \\ + These authors contributed equally to this work.
}

Received: 31 August 2020; Accepted: 19 October 2020; Published: 26 October 2020

\begin{abstract}
A simple one-step electrochemical deposition/activation of graphitic carbon nitride $\left(\mathrm{g}-\mathrm{C}_{3} \mathrm{~N}_{4}\right)$ is highly desired for sensor configurations and remains a great challenge. Herein, we attempt an electrochemical route to exfoliate the $\mathrm{g}-\mathrm{C}_{3} \mathrm{~N}_{4}$ nanosheets in an aqueous solution of $\mathrm{pH} 7.0$ for constructing a sensor, which is highly sensitive for the detection of serotonin (5-HT). The significance of our design is to exfoliate the g- $\mathrm{C}_{3} \mathrm{~N}_{4}$ nanosheets, a strong electrocatalyst for 5-HT detection. Investigations regarding the effect of neutral $\mathrm{pH}\left(\mathrm{pH}\right.$ 7.0) on the bulk g- $\mathrm{C}_{3} \mathrm{~N}_{4}$ and $\mathrm{g}-\mathrm{C}_{3} \mathrm{~N}_{4}$ nanosheets, physical characterization, and electrochemical studies were extensively carried out. We demonstrate that the g- $\mathrm{C}_{3} \mathrm{~N}_{4}$ nanosheets have a significant electrocatalytic effect for the 5-HT detection in a dynamic linear range from $500 \mathrm{pM}$ to $1000 \mathrm{nM}\left(R^{2}=0.999\right)$. The limit of detection and sensitivity of the designed 5-HT sensor was calculated to be $150 \mathrm{pM}$ and $1.03 \mu \mathrm{A} \mathrm{MM}^{-1} \mathrm{~cm}^{-2}$, respectively. The proposed sensor has great advantages such as high sensitivity, good selectivity, reproducibility, and stability. The constructed g- $\mathrm{C}_{3} \mathrm{~N}_{4}$ nanosheets-based sensor platform opens new feasibilities for the determination of 5-HT even at the picomolar/nanomolar concentration range.
\end{abstract}

Keywords: electrochemical activation; serotonin sensor; graphitic carbon nitride nanosheets

\section{Introduction}

Serotonin (5-hydroxytryptamine, 5-HT), a redox-active neurotransmitter, is one of the monoamine neurotransmitters prevailing in the mammalian central nervous system. Serotonin is directly associated with the body for regulation of mood, sexuality, emesis, pain, sleep, and appetite [1]. The fluctuations of 5-HT transmission are linked to several neurological disorders, e.g., multiple sclerosis, neuroblastoma, and Parkinson's disease [2]. The physiological levels of $5-\mathrm{HT}$ is $\sim 15 \mathrm{nM}$ in the human body fluids, and the altered levels can cause brain-related diseases. Therefore, it is crucial to rapidly detect 5-HT for the clinical diagnosis [1,3]. Among a plenty of conventional analytical techniques, the electrochemical system is highly favorable for clinical diagnosis due to prominent features such as reliability, affordability, portable, high selectivity, and good sensitivity without demanding any 
sophisticated process. Regardless of the above-mentioned advantages, the electrochemical approach for selective detection of 5-HT in practical applications is quite limited due to the interference with similar electroactive species (e.g., ascorbic acid). To achieve the goal of selective 5-HT detection, an effective strategy to negotiate the interfering species is of utmost importance.

In recent years, most of the literature studies have focused on the electrochemical sensors utilizing heavy-metal complexes along with the toxic material analysis for improving the charge transfer and fast signaling response [4,5]. To avoid the metal toxicity introducing the cost-effective carbon-based nanomaterials sensor are preferable and could also serve as the biocompatible substrate for further ex vivo and in vivo investigations [6]. To date, a lot of research works are reported on the electrochemical production of graphene-based nanomaterials and their electrochemical properties [7-9]. The electrochemically constructed high-purity monolayer structure of graphene is quite compatible with the design of sensors and many biomolecules could be readily detected in real samples as well. In our previous literature, we proposed the fabrication of a nanocomposite sensor for the ex vivo detection of dopamine neurotransmitters using brain tissue samples of a mouse Parkinson's disease model [10].

The design and fabrication of a metal-free carbon nanomaterials sensor, especially graphitic carbon nitride ( $\mathrm{g}-\mathrm{C}_{3} \mathrm{~N}_{4}$ ) with a two-dimensional (2D) layered structure, is an analogue of graphene. The intriguing physicochemical and electrochemical properties of the $g-C_{3} N_{4}$ shows great versatility for applications in catalysts, lithium-ion batteries, hydrogen, optoelectronic devices, and electrochemical sensors [11-15]. In this context, the synthesis of high-quality monolayer $\mathrm{g}-\mathrm{C}_{3} \mathrm{~N}_{4}$ nanosheets with reduced structural defects became very crucial, and many researchers are focused on this issue. Ultrathin $g-\mathrm{C}_{3} \mathrm{~N}_{4}$ nanosheets have recently been synthesized by prolonged ultra-sonication using a bulk $\mathrm{g}-\mathrm{C}_{3} \mathrm{~N}_{4}$ liquid exfoliation technique. Yet, this process might enable the preparation of a single-layered $\mathrm{g}-\mathrm{C}_{3} \mathrm{~N}_{4}$ structure, desirable for photocatalytic applications [16]. Cheng et al. [17] carried out chemical exfoliation of $\mathrm{g}-\mathrm{C}_{3} \mathrm{~N}_{4}$ sheets with sulfuric acid $\left(\mathrm{H}_{2} \mathrm{SO}_{4}\right)$ as a strong oxidizing agent. However, other literature has shown that ultrathin $\mathrm{g}-\mathrm{C}_{3} \mathrm{~N}_{4}$ nanosheets developed by an electrophoretic method using the mixture of $\mathrm{NaOH}$ and melamine [18]. This method requires high voltage and alkaline medium with the complicated synthetic procedure, which proves very tedious and yields only negligible quantities. All these reports reinforce that the $g-C_{3} N_{4}$ nanosheets are more suitable electrochemical catalysts for sensor applications. Jiang et al. [19] pioneered their research on electrochemical sensors using bulk g- $\mathrm{C}_{3} \mathrm{~N}_{4}$ to detect DA neurotransmitters. Gao et al. [20] also reported on the electrochemical $\mathrm{g}-\mathrm{C}_{3} \mathrm{~N}_{4}$ nanosheets sensor for the determination of cadmium. The porous g- $\mathrm{C}_{3} \mathrm{~N}_{4}$-based composite was used for ascorbic acid detection [21]. The above reports consist of complex synthesis procedures and often urge researchers to focus on an easy electrochemical exfoliation of g- $\mathrm{C}_{3} \mathrm{~N}_{4}$ nanosheets. Electrochemical exfoliation, which requires no costly equipment and is faster, more effective, and more controllable and is more appropriate to exfoliate $\mathrm{g}-\mathrm{C}_{3} \mathrm{~N}_{4}$ nanosheets from bulk g- $\mathrm{C}_{3} \mathrm{~N}_{4}[22,23]$. Moreover, there is no reported literature on the electrochemical determination of 5-HT using the $\mathrm{g}-\mathrm{C}_{3} \mathrm{~N}_{4}$ nanosheets.

Our aim is to develop cost-effective $\mathrm{g}-\mathrm{C}_{3} \mathrm{~N}_{4}$ nanosheets by simple electrochemical activation method. To our knowledge, this is the first report for the electrochemical 5-HT detection using g- $\mathrm{C}_{3} \mathrm{~N}_{4}$ nanosheets (Scheme 1).

Initially, the bulk $\mathrm{g}-\mathrm{C}_{3} \mathrm{~N}_{4}$ was drop-casted onto the glassy carbon electrode (GCE) surface and electrochemically activated at the applied potential of $1.75 \mathrm{~V}$ in neutral $\mathrm{pH}$ conditions ( $\mathrm{pH} 7.0)$ to exfoliate $\mathrm{g}-\mathrm{C}_{3} \mathrm{~N}_{4}$ nanosheets from the bulk $\mathrm{g}-\mathrm{C}_{3} \mathrm{~N}_{4}$. The sensor has been optimized by varying $\mathrm{pH}$ and applied potential. The high electro-catalytic activity of the $g-C_{3} N_{4}$ nanosheets enhances the sensitivity and selectivity of the 5-HT sensors. 


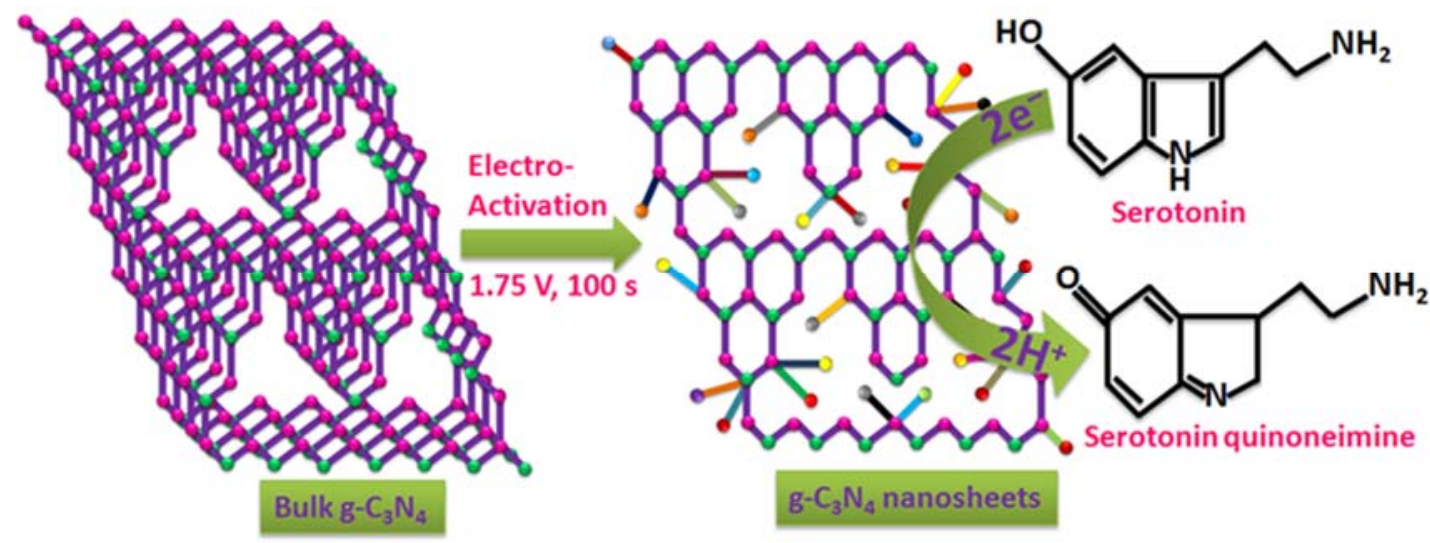

Scheme 1. Schematic representation of a one-step electrochemical activation of $g-C_{3} N_{4}$ nanosheets for 5-HT detection.

\section{Materials and Methods}

\subsection{Reagents and Instruments}

Melamine, serotonin (5-HT), tyrosine (Tyr), glucose (GLU), ascorbic acid (AA), uric acid (UA), sodium phosphate dibasic $\left(\mathrm{Na}_{2} \mathrm{HPO}_{4}\right)$, sodium phosphate monobasic $\left(\mathrm{NaH}_{2} \mathrm{PO}_{4}\right)$, sodium hydroxide $(\mathrm{NaOH})$, and phosphoric acid $\left(\mathrm{H}_{3} \mathrm{PO}_{4}\right)$ were purchased from Sigma Aldrich, USA. The 5-HT solution was freshly prepared each day and protected from light during use.

All chemicals were of analytical grade and were used as received. An amount of $0.1 \mathrm{M}$ phosphate buffer solution (PBS) at different $\mathrm{pH}$ values was prepared by mixing a solution of $\mathrm{Na}_{2} \mathrm{HPO}_{4}$ and $\mathrm{NaH}_{2} \mathrm{PO}_{4}$ at different proportions, the $\mathrm{pH}$ adjusted with $\mathrm{NaOH}$ or $\mathrm{H}_{3} \mathrm{PO}_{4}$. All aqueous solutions were prepared using deionized water (Milli-Q water purifying system, $18 \mathrm{M} \Omega \cdot \mathrm{cm}$ ).

Electrochemical experiments including cyclic voltammetry $(\mathrm{CV})$ and chronoamperometry were carried out with a CompactStat potentiostat (Ivium Technologies B.V., De Zaale 11, 5612 AJ Eindhoven, The Netherlands) employing a conventional three-electrode system: a bare glassy carbon electrode (GCE, $3 \mathrm{~mm}$ in diameter) as the working electrode, $\mathrm{Ag} / \mathrm{AgCl}$ as the reference electrode, and a platinum wire as the auxiliary electrode. The bulk g- $\mathrm{C}_{3} \mathrm{~N}_{4}$ was electrochemically activated on indium tin oxide (ITO) substrates to study their surface characteristics by a field-emission scanning electron microscopy (FE-SEM, Hitachi S-4200, Chiyoda, Japan) at $15 \mathrm{kV}$ and $150 \mathrm{~W}$.

\subsection{Sensor Preparation}

The bulk g- $\mathrm{C}_{3} \mathrm{~N}_{4}$ was synthesized through the direct heating process, as reported previously [24]. Briefly, $10 \mathrm{~g}$ of melamine was heated at $550{ }^{\circ} \mathrm{C}$ for $2 \mathrm{~h}$ under air atmosphere. The resultant yellow powders were then washed with deionized water and ethanol several times. Finally, the powers were dried at $60^{\circ} \mathrm{C}$ in air overnight. The as-obtained bulk g- $\mathrm{C}_{3} \mathrm{~N}_{4}$ was dispersed in water $(3 \mathrm{mg} \mathrm{mL}-1)$ and sonicated for $2 \mathrm{~h}$. A bare GCE was polished to using $0.05 \mu \mathrm{m}$ alumina powder on a polishing cloth with water rinsing and dried at room temperature. Some $5 \mu \mathrm{L}$ of $3 \mathrm{mg} \mathrm{mL}^{-1}$ bulk g- $\mathrm{C}_{3} \mathrm{~N}_{4}$ suspensions were drop-casted on the GCE surface and allowed to dry in ambient temperature $\left(25^{\circ} \mathrm{C}\right)$ conditions. The bulk g- $\mathrm{C}_{3} \mathrm{~N}_{4}$ modified GCE was subjected to a constant potential of $1.75 \mathrm{~V}$ for $100 \mathrm{~s}$ (optimal) in aqueous solution ( $\mathrm{pH}$ 7.0) to get the $\mathrm{g}_{-} \mathrm{C}_{3} \mathrm{~N}_{4}$ nanosheets. The prepared sensor was thoroughly rinsed with deionized water followed by drying in air. Finally, the sensor was represented as $g-C_{3} N_{4}$ nanosheets and was stored at $4{ }^{\circ} \mathrm{C}$ in the refrigerator when not in use. Moreover, an additional $5 \mu \mathrm{L}$ of $3 \mathrm{mg} \mathrm{mL}^{-1}$ bulk g- $\mathrm{C}_{3} \mathrm{~N}_{4}$ suspensions were drop-casted on the GCE surface and allowed to dry in ambient temperature $\left(25^{\circ} \mathrm{C}\right)$ conditions and used as a bulk g- $\mathrm{C}_{3} \mathrm{~N}_{4}$-modified GCE. 


\section{Results and Discussion}

\subsection{Physical Characterization of $g-C_{3} N_{4}$ Nanosheets}

The surface morphology of bulk g- $\mathrm{C}_{3} \mathrm{~N}_{4}$ and the electrochemically activated g- $\mathrm{C}_{3} \mathrm{~N}_{4}$ nanosheets characterized by FE-SEM are shown in Figure 1.

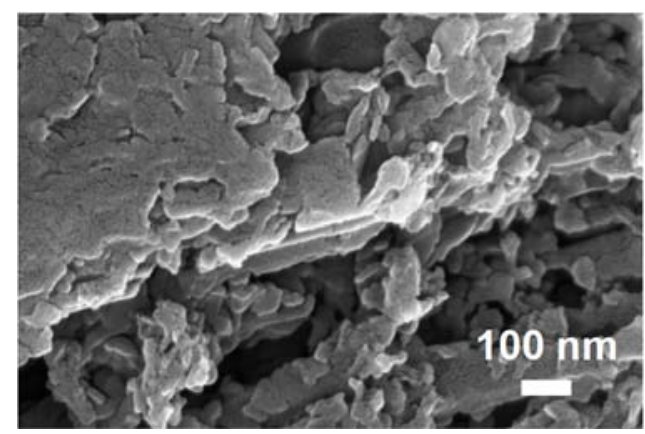

(a)

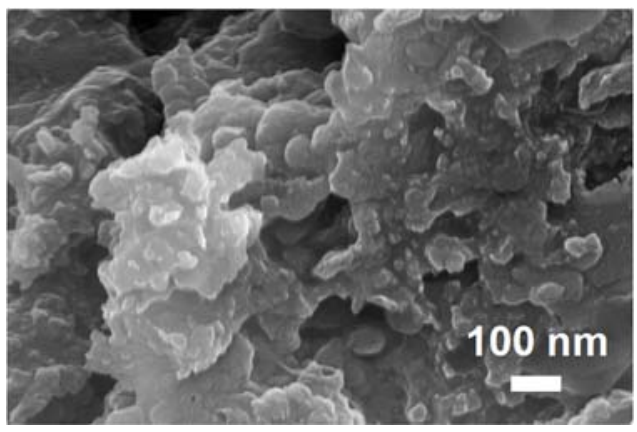

(b)

Figure 1. FE-SEM images of (a) bulk $g-C_{3} N_{4}$ and (b) electrochemically activated g- $C_{3} N_{4}$ nanosheets.

The bulk g- $\mathrm{C}_{3} \mathrm{~N}_{4}$ possesses a folded grain-like morphology with numerous agglomerates forming a thick layer, similar to the previous reports of the other researchers [16]. After electrochemical activation, the g- $\mathrm{C}_{3} \mathrm{~N}_{4}$ nanosheets revealed a porous 2D-like network with a large surface area. The $\mathrm{g}-\mathrm{C}_{3} \mathrm{~N}_{4}$ nanosheets show a sponge-like morphology due to the heavily smashed surfaces, which indicates the successful exfoliation of bulk g- $\mathrm{C}_{3} \mathrm{~N}_{4}$ to $g-\mathrm{C}_{3} \mathrm{~N}_{4}$ nanosheets.

\subsection{Optimization of $g-C_{3} N_{4}$ Nanosheets Synthesis}

Herein, we attempted a simple electrochemical approach to exfoliate g- $\mathrm{C}_{3} \mathrm{~N}_{4}$ nanosheets from the bulk g- $\mathrm{C}_{3} \mathrm{~N}_{4}$ in aqueous solution (pH 7.0) without any surfactants. The effect of various applied potential against time in seconds was investigated by the chronoamperometric experiments. The optimal applied potential that could exfoliate the bulk g- $\mathrm{C}_{3} \mathrm{~N}_{4}$ into g- $\mathrm{C}_{3} \mathrm{~N}_{4}$ nanosheets was determined to be $1.75 \mathrm{~V}$ for 100 s, as shown in Figure 2a.

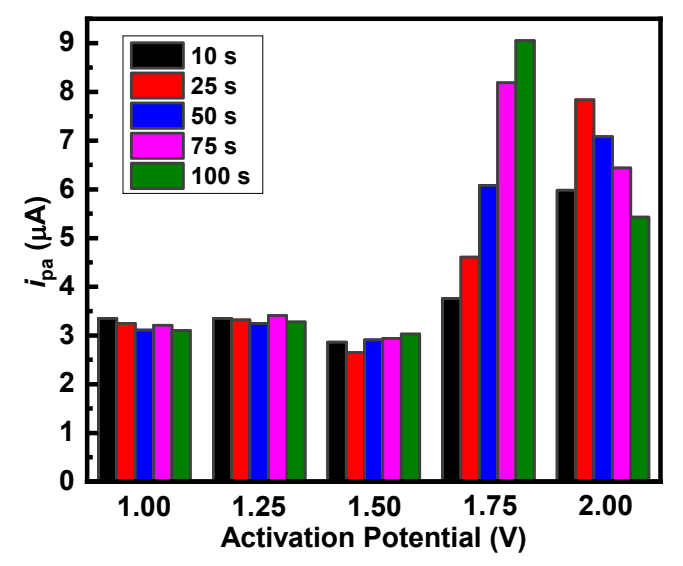

(a)

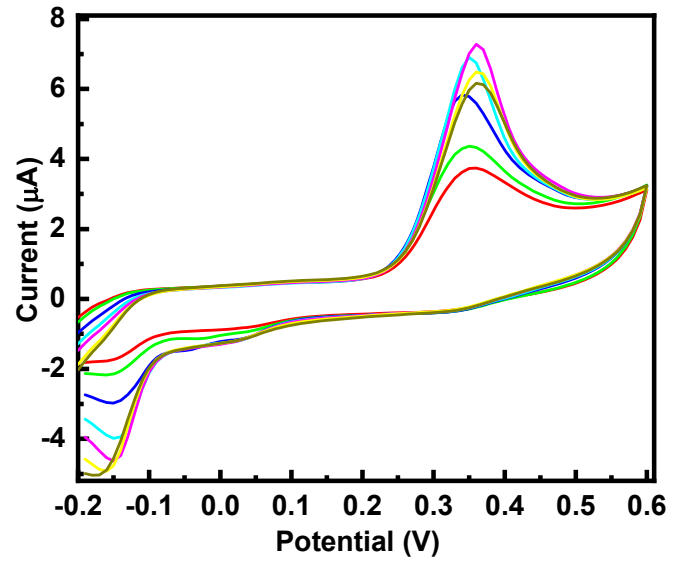

(b)

Figure 2. Cont. 


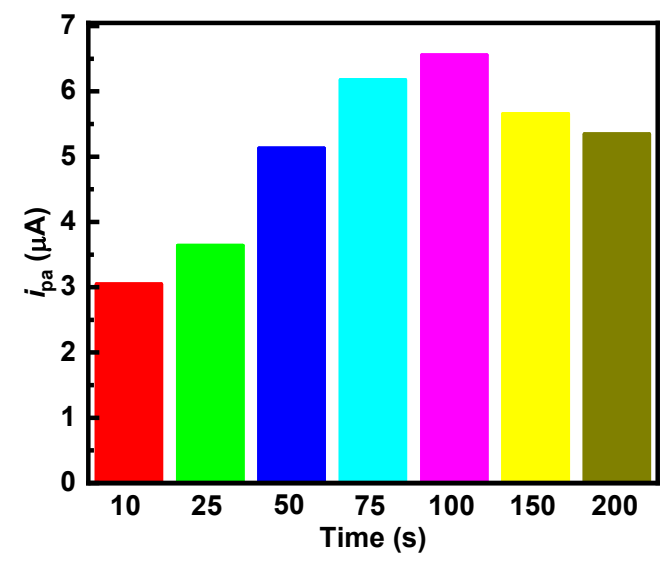

(c)



(d)

Figure 2. (a) Amperometric current response of 5-HT oxidation using various applied potential against different times. (b) CVs of g- $\mathrm{C}_{3} \mathrm{~N}_{4}$ nanosheets were carried out at a constant applied potential of $1.75 \mathrm{~V}$ against different times. (c) The corresponding current response of 5-HT oxidation against different times. (d) CVs of (i) bare GCE, (ii) bulk g- $\mathrm{C}_{3} \mathrm{~N}_{4}$, and (iii) $\mathrm{g}-\mathrm{C}_{3} \mathrm{~N}_{4}$ nanosheets in $0.1 \mathrm{M}$ PBS (pH 7.0) containing $30 \mu \mathrm{M}$ 5-HT at a scan rate of $50 \mathrm{mVs}^{-1}$. Inset: $\mathrm{CV}$ curves of $\mathrm{g}-\mathrm{C}_{3} \mathrm{~N}_{4}$ nanosheets in the (i) absence and (ii) presence of $30 \mu \mathrm{M} 5-\mathrm{HT}$.

The significant enhancement in the electrochemical sensing performance reveals a well-differentiated very sharp oxidation peak that remains constant at various potentials and at various times, as shown in Figure $2 b$ and $c$. The strong electrocatalytic properties of the formed $g-C_{3} \mathrm{~N}_{4}$ nanosheets are thin enough to penetrate electrons [25]. These results were similar to the electrochemical activation of carbon-based nanomaterials [26,27]. Therefore, the constant potential of $1.75 \mathrm{~V}$ for $100 \mathrm{~s}$ is ideal to enable further electrochemical measurements with the $g-\mathrm{C}_{3} \mathrm{~N}_{4}$ nanosheets electrodes.

The electrochemical performance of 5-HT on bare GCE (i), bulk g- $\mathrm{C}_{3} \mathrm{~N}_{4}$ (ii), and g- $\mathrm{C}_{3} \mathrm{~N}_{4}$ nanosheets (iii) modified electrodes were evaluated by CV experiments in PBS (pH 7.0) containing $30 \mu \mathrm{M} 5-\mathrm{HT}$ at the scan rate of $50 \mathrm{mVs}^{-1}$, and the results are shown in Figure $2 \mathrm{~d}$. The bare GCE and the bulk $\mathrm{g}^{-} \mathrm{C}_{3} \mathrm{~N}_{4}$ shows irreversible oxidation for 5-HT with anodic peak current of $1.08 \mu \mathrm{A}$ and $1.81 \mu \mathrm{A}$ at $0.37 \mathrm{~V}$, respectively. While, the g- $\mathrm{C}_{3} \mathrm{~N}_{4}$ nanosheets modified GCE shows a quasi-reversible redox behavior for 5-HT with anodic peak current of $8.26 \mu \mathrm{A}$ at $0.35 \mathrm{~V}$ and cathodic peak current of $-5.45 \mu \mathrm{A}$ at $-0.15 \mathrm{~V}$. The $\mathrm{g}-\mathrm{C}_{3} \mathrm{~N}_{4}$ nanosheets modified GCE display an increased current response, and the peak potential shift to less positive as compared to the bulk g- $\mathrm{C}_{3} \mathrm{~N}_{4}$. The electrode oxidation reaction involves a two-electron process, which is accompanied by a transfer of two protons, forming 5-HT quinoneimine. The new reduction peak observed only for the $g-C_{3} N_{4}$ nanosheets $(-0.15 \mathrm{~V})$ is most likely due to the reduction in the quinone group on 5-HT quinoneimine [28]. The reduction reaction, which occurs within the chosen potential window is due to the fast electron transfer property of the g- $\mathrm{C}_{3} \mathrm{~N}_{4}$ nanosheets. The electrochemically active surface areas were also calculated by using the Randles-Sevcik equation (Equation (1)).

$$
i_{\mathrm{pa}}=2.69 \times 10^{5} n^{3 / 2} A C D^{1 / 2} v^{1 / 2}
$$

where, $i_{\mathrm{pa}}$ is the anodic peak current (A), $n$ is the number of electrons $(n=2), A$ is the electrochemically active surface area $\left(\mathrm{cm}^{2}\right), D$ is the diffusion coefficient $\left(9.0154 \times 10^{-6} \mathrm{~cm}^{2} \mathrm{~s}^{-1}\right), C$ is the concentration of 5 -HT $\left(30 \times 10^{-6} \mathrm{M}\right)$, and $v$ is the scan rate $\left(\mathrm{V} \mathrm{s}^{-1}\right)$. According to this equation, the electrochemically active surface area of the bare GCE, bulk g- $\mathrm{C}_{3} \mathrm{~N}_{4}$, and g- $\mathrm{C}_{3} \mathrm{~N}_{4}$ nanosheets modified electrodes were calculated to be $0.071 \mathrm{~cm}^{2}, 0.118 \mathrm{~cm}^{2}$, and $0.539 \mathrm{~cm}^{2}$, respectively. The $\mathrm{g}-\mathrm{C}_{3} \mathrm{~N}_{4}$ nanosheets modified electrodes possess higher electroactive surface area, which enhances the oxidation of 5-HT. The feasibility the 
g- $\mathrm{C}_{3} \mathrm{~N}_{4}$ nanosheets modified GCE towards the catalytic oxidation of 5-HT was examined in the absence and presence of 5-HT in PBS. In the inset Figure $2 \mathrm{~d}$, the g- $\mathrm{C}_{3} \mathrm{~N}_{4}$ nanosheets show no redox peak in the absence of 5-HT, and in the presence of $30 \mu \mathrm{M} 5-\mathrm{HT}$, a redox peak was observed, due to the electrocatalytic activity towards the 5-HT. This result indicates that the g- $\mathrm{C}_{3} \mathrm{~N}_{4}$ nanosheets modified GCE in 5-HT produced 3.5 and 6.5 times more current response $(6.64 \mu \mathrm{A})$ than the bulk $\mathrm{g}-\mathrm{C}_{3} \mathrm{~N}_{4}$ $(1.85 \mu \mathrm{A})$ and the bare GCE $(1.10 \mu \mathrm{A})$. Therefore, the g- $\mathrm{C}_{3} \mathrm{~N}_{4}$ nanosheets modified GCE could serve as a beneficial nanomaterial for sensitive 5 -HT detection.

\subsection{Optimization of 5-HT Sensors}

In order to determine the optimum conditions, chronoamperometric measurements under various applied potential, and at various $\mathrm{pH}$ levels, were explored. From the potential range from $0.30 \mathrm{~V}$ to $0.45 \mathrm{~V}$ along with the addition of $100 \mathrm{nM} 5-\mathrm{HT}$ in $0.1 \mathrm{M} \mathrm{PBS}$ (pH 7.0) was evaluated and the results are shown in Figure 3a.

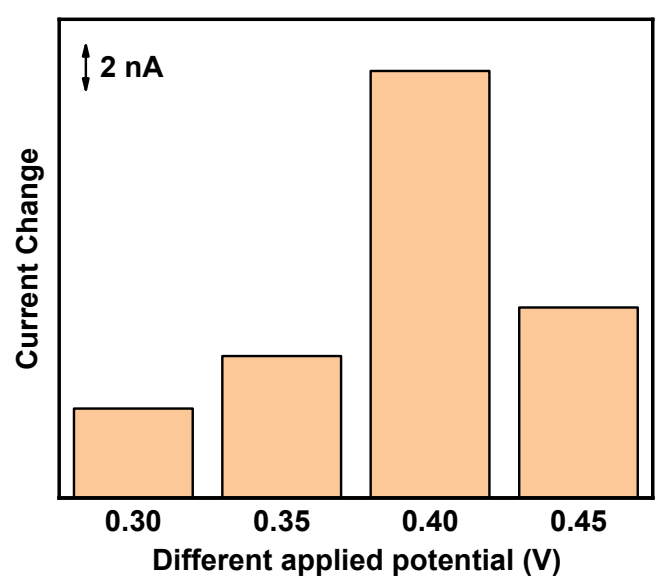

(a)

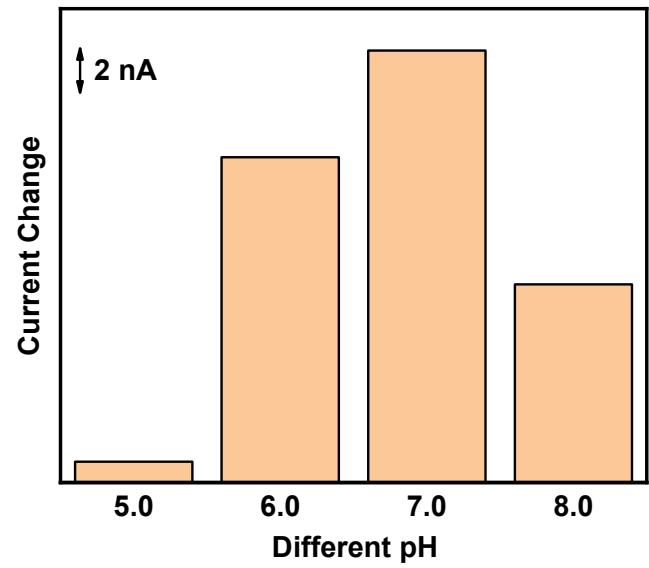

(b)

Figure 3. (a) Current change under different applied potential for the $g-\mathrm{C}_{3} \mathrm{~N}_{4}$ nanosheets in $0.1 \mathrm{M}$ PBS (pH 7.0) with the addition of $100 \mathrm{nM}$ 5-HT. (b) Current change under different $\mathrm{pH}$ values for the g- $\mathrm{C}_{3} \mathrm{~N}_{4}$ nanosheets in $0.1 \mathrm{M}$ PBS with the addition of $100 \mathrm{nM} 5-\mathrm{HT}$ at an applied potential of $0.40 \mathrm{~V}$.

Figure 3a reveals the highest current response at $0.40 \mathrm{~V}$. The optimum $\mathrm{pH}$ for the 5-HT sensor was measured in the $\mathrm{pH}$ range from 5.0 to 8.0 with the addition of $100 \mathrm{nM} \mathrm{5-HT}$ at an applied potential of $0.40 \mathrm{~V}$ and are depicted in Figure $3 \mathrm{~b}$. Figure $3 \mathrm{~b}$ shows maximum current responses for the sensor in PBS pH 7.0. Therefore, the optimized applied potential of $0.40 \mathrm{~V}$ and $\mathrm{pH}$ of 7.0 were chosen for the following experiments.

\subsection{Calibration Plots}

The analytical performance and calibration plots for bulk g- $\mathrm{C}_{3} \mathrm{~N}_{4}$ and $\mathrm{g}-\mathrm{C}_{3} \mathrm{~N}_{4}$ nanosheets towards 5-HT detection are presented in Figure 4.

The amperometric measurements were carried out to examine the constructed sensor upon sequential addition of 5-HT aliquots in 0.1 M PBS ( $\mathrm{pH} 7.0$ ), at an operating potential of $0.4 \mathrm{~V}$. After each addition of 5-HT, the current response increased within five seconds (Figure 4a). The 5-HT calibration curves were constructed; each error bar shown on the curve represents one standard deviation over five measurements, and the values are expressed in $95 \%$ confidence intervals. In the calibration curve (Figure $4 \mathrm{~b}$ ), the sensor demonstrates a dynamic linear range from $500 \mathrm{pM}$ to $1000 \mathrm{nM}$, and the linear regression equation for $\mathrm{g}-\mathrm{C}_{3} \mathrm{~N}_{4}$ nanosheets is $i(\mathrm{nA})=0.476 C_{5-\mathrm{HT}}(\mathrm{nM})+0.072\left(R^{2}=0.999\right)$. The limit of detection for $\mathrm{g}-\mathrm{C}_{3} \mathrm{~N}_{4}$ nanosheets was calculated to be $150 \mathrm{pM}(\mathrm{S} / \mathrm{N}=3)$, the sensitivity was estimated 
to be $1.03 \mu \mathrm{A} \mu \mathrm{M}^{-1} \mathrm{~cm}^{-2}$, the limit of detection of the bulk $\mathrm{g}-\mathrm{C}_{3} \mathrm{~N}_{4}$ was $1.88 \mathrm{nM}$, and the sensitivity was $0.63 \mu \mathrm{A} \mu \mathrm{M}^{-1} \mathrm{~cm}^{-2}$. The sensitivity of $\mathrm{g}-\mathrm{C}_{3} \mathrm{~N}_{4}$ nanosheets is approximately 1.6 times higher than the bulk g- $\mathrm{C}_{3} \mathrm{~N}_{4}$. The results were compared with studies reported previously and are given in Table 1 .

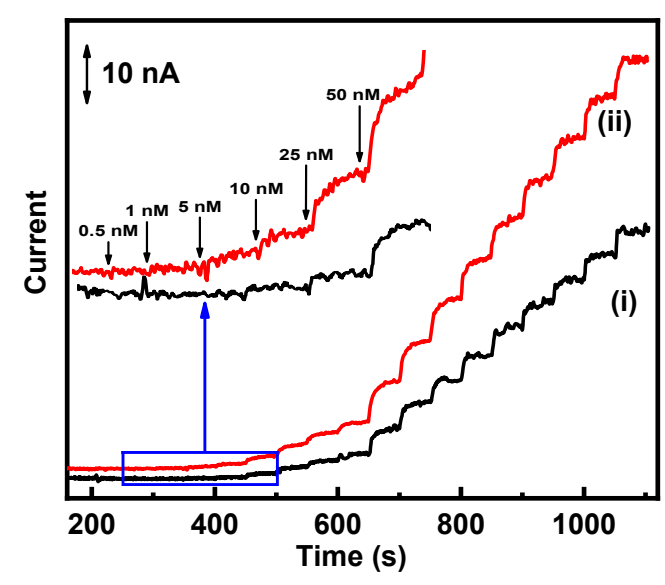

(a)

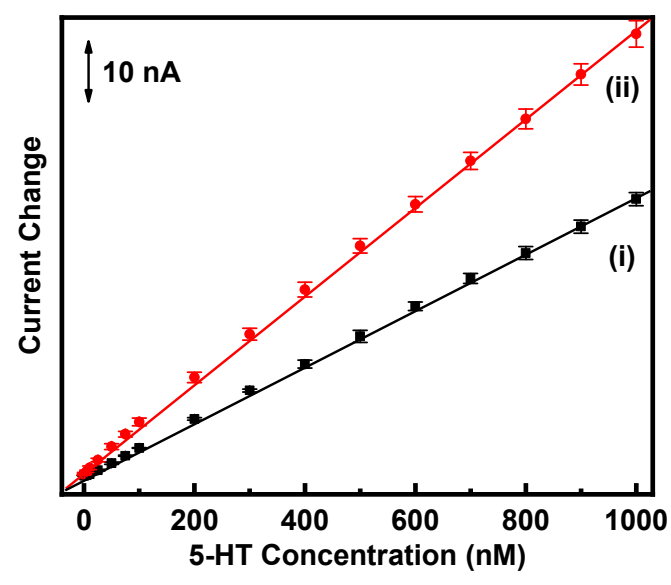

(b)

Figure 4. (a) Amperometric response of (i) bulk g- $\mathrm{C}_{3} \mathrm{~N}_{4}$ and (ii) $\mathrm{g}-\mathrm{C}_{3} \mathrm{~N}_{4}$ nanosheets at $0.40 \mathrm{~V}$ in $0.1 \mathrm{M}$ PBS (pH 7.0) with successive addition of 5-HT. Inset: The concentrations of 5-HT (0.5 nM, $1 \mathrm{nM}, 5 \mathrm{nM}$, $10 \mathrm{nM}, 25 \mathrm{nM}$, and $50 \mathrm{nM}$ ); (b) the corresponding calibration curves.

Table 1. Comparison of the prepared sensor with previously reported studies for 5-HT detection.

\begin{tabular}{|c|c|c|c|c|c|}
\hline Modified Electrode & Method & $\begin{array}{l}\text { Limit of } \\
\text { Detection } \\
\text { (nM) }\end{array}$ & $\begin{array}{c}\text { Dynamic } \\
\text { Linear Range } \\
\text { (nM) }\end{array}$ & $\begin{array}{c}\text { Sensitivity } \\
\left(\mu \mathrm{A} \mu \mathbf{M}^{-1} \mathrm{~cm}^{-2}\right)\end{array}$ & Ref. \\
\hline AuAg-GR ${ }^{1}$ & Amperometry & 1.6 & $2.7-4820$ & 0.766 & [1] \\
\hline $\mathrm{RGO}-\mathrm{Co}_{3} \mathrm{O}_{4}{ }^{2}$ & $\mathrm{DPV}^{5}$ & 48.7 & $100-51,000$ & 2.2 & [29] \\
\hline MCM-41-COOH/Au@nano-CILPE ${ }^{3}$ & $\mathrm{SWV}^{6}$ & 100 & $200-20,000$ & - & [30] \\
\hline $\mathrm{Fe}_{3} \mathrm{O}_{4}-\mathrm{MWCNT}-$ poly(BCG)/GCE ${ }^{4}$ & DPV & 80 & $500-100,000$ & - & [31] \\
\hline $\mathrm{GCE} / \mathrm{g}-\mathrm{C}_{3} \mathrm{~N}_{4}$ nanosheets & Amperometry & 0.15 & $0.5-1000$ & 1.03 & This study \\
\hline
\end{tabular}

1 AuAg-GR: graphene-encapsulated AuAg alloy; ${ }^{2} \mathrm{RGO} \mathrm{Co}_{3} \mathrm{O}_{4}$ : reduced graphene oxide-cobalt oxide; ${ }^{3}$ MCM-41-COOH/Au@nano-CILPE: carboxyl-functionalized mesoporous molecular sieve/colloidal gold modified nano-carbon ionic liquid paste electrode; ${ }^{4} \mathrm{Fe}_{3} \mathrm{O}_{4}$-MWCNT-poly(BCG)/GCE: iron oxide-multiwalled carbon nanotubes-poly(bromocresol green); ${ }^{5} \mathrm{DPV}$ : differential pulse voltammetry; ${ }^{6} \mathrm{SWV}$ : square pulse voltammetry.

Our g- $\mathrm{C}_{3} \mathrm{~N}_{4}$ nanosheet results exhibit better limit of detection, and dynamic linear range and sensitivity is comparable with the studies reported previously. Therefore, these results suggest that the g- $\mathrm{C}_{3} \mathrm{~N}_{4}$ nanosheets demonstrate better electrocatalytic activity towards 5-HT detection.

\subsection{Selectivity Study}

Poor selectivity is a critical issue when the sensors are applied to real biological samples for 5-HT detection. The electrochemically synthesized carbon-based nanomaterials are likely to have a stronger electrocatalytic effect than the noble metals $[9,27]$. Therefore, the selectivity of the sensor was explored to study the interference towards $5-\mathrm{HT}$ detection at the potential of $0.4 \mathrm{~V}$. Figure 5 displays the amperometric measurements recorded on the g- $\mathrm{C}_{3} \mathrm{~N}_{4}$ nanosheets electrode for the successive additions of $2 \mu \mathrm{M}$ of AA, UA, Tyr, GLU, and finally, $0.2 \mu \mathrm{M}$ of 5-HT.

The designed sensor shows a rapid and sharp increase in the current response for 5-HT, and there were no distinct current changes or interferences by other substances. The g- $C_{3} N_{4}$ nanosheets favorably enhance electrostatic interaction only with positively charged 5- $\mathrm{HT}$ and readily creates an electrostatic repulsion for AA (negatively charged at physiological $\mathrm{pH}$ ) [32,33]. This result indicates that the $\mathrm{g}-\mathrm{C}_{3} \mathrm{~N}_{4}$ nanosheets can be favorable for practical sensor applications. 


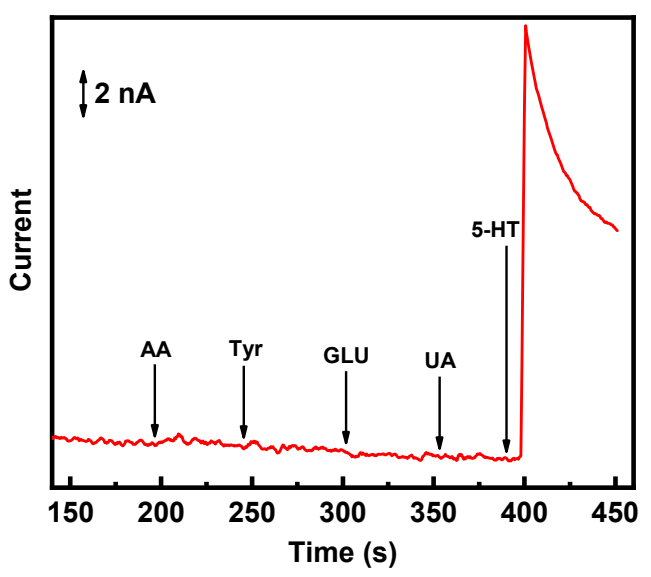

Figure 5. Amperometric response of $\mathrm{g}-\mathrm{C}_{3} \mathrm{~N}_{4}$ nanosheets for the addition of $2 \mu \mathrm{M}$ AA, $2 \mu \mathrm{M}$ Tyr, $2 \mu \mathrm{M}$ GLU, $2 \mu \mathrm{M}$ UA, and $0.2 \mu \mathrm{M}$ 5-HT in $0.1 \mathrm{M}$ PBS (pH 7.0) at an applied potential of $0.4 \mathrm{~V}$.

\subsection{Reproducibility and Stability}

Reproducibility and storage stability are important characteristics for 5-HT detection, and the designed sensor was examined initially and after 30 days through the amperometric experiments. The reproducibility of the four $\mathrm{g}-\mathrm{C}_{3} \mathrm{~N}_{4}$ nanosheets electrodes was recorded from the current response towards $100 \mathrm{nM} 5-\mathrm{HT}$, and the relative standard deviation (RSD) was determined to be $5.08 \%$. The storage stability of the sensor was measured by the current response of $100 \mathrm{nM} 5-\mathrm{HT}$. After 30 days, the decrease in current response was sustained over 95\% of its initial current response value. The proposed serotonin sensor showed an acceptable reproducibility and long-term storage stability for the detection of 5-HT.

\section{Conclusions}

A cost-effective and a simple one-step electrochemical activation of $g-C_{3} N_{4}$ nanosheets from bulk g- $\mathrm{C}_{3} \mathrm{~N}_{4}$ in aqueous solution (pH 7.0) was carried out to fabricate the 5-HT sensor. The $\mathrm{g}^{-} \mathrm{C}_{3} \mathrm{~N}_{4}$ nanosheets modified GCE possesses a high electroactive surface area, which ensures fast electron transfer. When compared with bulk g- $\mathrm{C}_{3} \mathrm{~N}_{4}$, the electrochemically activated g- $\mathrm{C}_{3} \mathrm{~N}_{4}$ nanosheets exhibit a strong electrocatalytic effect, which improves the sensitivity and selectivity towards 5-HT. In addition, the proposed sensor demonstrates good dynamic linear range, fast response, and picomolar detection limit. The prominent characteristics of $\mathrm{g}-\mathrm{C}_{3} \mathrm{~N}_{4}$ nanosheets open new opportunities for the easy fabrication of portable electrochemical sensors. Therefore, the designed sensor is a promising candidate for the ex vivo and in vivo 5-HT sensing applications.

Author Contributions: V.K., T.R., and S.L. have worked together in designing and performing the experiments as well as analyzing the data and writing the original draft. T.R. and D.T. have contributed to writing-review and editing. S.K., J.L., D.T., and S.-C.C. have reviewed and finalized the manuscript. All authors have read and agreed to the published version of the manuscript.

Funding: This work was supported by the National Research Foundation of Korea (NRF) grant funded by the Korea government (MSIT) (No. NRF-2019R1F1A1063034) and the BK21 Plus program through the NRF funded by the Ministry of Education (No. 10Z20130000004). This study was part of the project titled "Omics based on fishery disease control, technology development, and industrialization (20150242)," funded by the Ministry of Oceans and Fisheries, Korea.

Conflicts of Interest: The authors declare no conflict of interest. 


\section{References}

1. Thanh, T.D.; Balamurugan, J.; Hien, H.V.; Kim, N.H.; Lee, J.H. A novel sensitive sensor for serotonin based on high-quality of AuAg nanoalloy encapsulated graphene electrocatalyst. Biosens. Bioelectron. 2017, 96, 186-193. [CrossRef] [PubMed]

2. Wang, Y.; Wang, S.; Tao, L.; Min, Q.; Xiang, J.; Wang, Q.; Xie, J.; Yue, Y.; Wu, S.; Li, X.; et al. A disposable electrochemical sensor for simultaneous determination of norepinephrine and serotonin in rat cerebrospinal fluid based on MWNTs-ZnO/chitosan composites modified screen-printed electrode. Biosens. Bioelectron. 2015, 65, 31-38. [CrossRef] [PubMed]

3. Artigas, F.; Sarrias, M.J.; Martinez, E.; Gelpi, E. Serotonin in body fluids: Characterization of human plasmatic and cerebrospinal fluid pools by means of a new HPLC method. Life Sci. 1985, 37, 441-447. [CrossRef]

4. Gupta, R.; Gamare, J.S.; Pandey, A.K.; Tyagi, D.; Kamat, J.V. Highly Sensitive Detection of Arsenite Based on Its Affinity toward Ruthenium Nanoparticles Decorated on Glassy Carbon Electrode. Anal. Chem. 2016, 88, 2459-2465. [CrossRef] [PubMed]

5. Ananthi, A.; Kumar, S.S.; Phani, K.L. Facile one-step direct electrodeposition of bismuth nanowires on glassy carbon electrode for selective determination of folic acid. Electrochim. Acta 2015, 151, 584-590. [CrossRef]

6. Yang, C.; Denno, M.E.; Pyakurel, P.; Venton, B.J. Recent trends in carbon nanomaterial-based electrochemical sensors for biomolecules: A review. Anal. Chim. Acta 2015, 887, 17-37. [CrossRef] [PubMed]

7. Guo, H.L.; Wang, X.F.; Qian, Q.Y.; Wang, F.B.; Xia, X.H. A green approach to the synthesis of graphene nanosheets. ACS Nano 2009, 3, 2653-2659. [CrossRef]

8. Cao, J.; He, P.; Mohammed, M.A.; Zhao, X.; Young, R.J.; Derby, B.; Kinloch, I.A.; Dryfe, R.A.W. Two-Step Electrochemical Intercalation and Oxidation of Graphite for the Mass Production of Graphene Oxide. J. Am. Chem. Soc. 2017, 139, 17446-17456. [CrossRef]

9. Zhang, Z.; Yan, J.; Jin, H.; Yin, J. Tuning the reduction extent of electrochemically reduced graphene oxide electrode film to enhance its detection limit for voltammetric analysis. Electrochim. Acta 2014, 139, $232-237$. [CrossRef]

10. Vijayaraj, K.; Dinakaran, T.; Lee, Y.; Kim, S.; Kim, H.S.; Lee, J.; Chang, S.-C. One-step construction of a molybdenum disulfide/multi-walled carbon nanotubes/polypyrrole nanocomposite sensor for the ex-vivo detection of dopamine in mouse brain tissue. Biochem. Biophys. Res. Commun. 2017, 494, 181-187. [CrossRef]

11. Xiong, M.; Rong, Q.; Meng, H.; Zhang, X. Two-dimensional graphitic carbon nitride nanosheets for biosensing applications. Biosens. Bioelectron. 2017, 89, 212-223. [CrossRef] [PubMed]

12. Lin, Z.; Wang, X. Nanostructure engineering and doping of conjugated carbon nitride semiconductors for hydrogen photosynthesis. Angew. Chem. Int. Ed. Engl. 2013, 52, 1735-1738. [CrossRef]

13. Zhang, Y.; Mori, T.; Ye, J.; Antonietti, M. Phosphorus-doped carbon nitride solid: Enhanced electrical conductivity and photocurrent generation. J. Am. Chem. Soc. 2010, 132, 6294-6295. [CrossRef]

14. Zhou, D.; Wang, M.; Dong, J.; Ai, S. A Novel Electrochemical Immunosensor Based on Mesoporous Graphitic Carbon Nitride for Detection of Subgroup J of Avian Leukosis Viruses. Electrochim. Acta 2016, 205, 95-101. [CrossRef]

15. Zhang, J.H.; Wei, M.J.; Wei, Z.W.; Pan, M.; Su, C.-Y. Ultrathin Graphitic Carbon Nitride Nanosheets for Photocatalytic Hydrogen Evolution. ACS Appl. Nano Mater. 2020, 3, 1010-1018. [CrossRef]

16. Zhang, X.; Xie, X.; Wang, H.; Zhang, J.; Pan, B.; Xie, Y. Enhanced photoresponsive ultrathin graphitic-phase C3N4 nanosheets for bioimaging. J. Am. Chem. Soc. 2013, 135, 18-21. [CrossRef]

17. Cheng, F.; Wang, H.; Dong, X. The amphoteric properties of g-C3N4 nanosheets and fabrication of their relevant heterostructure photocatalysts by an electrostatic re-assembly route. Chem. Commun. 2015, 51, 7176-7179. [CrossRef]

18. Lu, Q.; Deng, J.; Hou, Y.; Wang, H.; Li, H.; Zhang, Y. One-step electrochemical synthesis of ultrathin graphitic carbon nitride nanosheets and their application to the detection of uric acid. Chem. Commun. 2015, 51, 12251-12253. [CrossRef]

19. Jiang, T.; Jiang, G.; Huang, Q.; Zhou, H. High-sensitive detection of dopamine using graphitic carbon nitride by electrochemical method. Mater. Res. Bull. 2016, 74, 271-277. [CrossRef]

20. Gao, W.; Wang, X.; Li, P.; Wu, Q.; Qi, F.; Wu, S.; Yu, Y.; Ding, K. Highly sensitive and selective detection of cadmium with a graphite carbon nitride nanosheets/Nafion electrode. RSC Adv. 2016, 6, 113570-113575. [CrossRef] 
21. Wu, Y.; Yang, Y.; Lei, W.; Li, C.; Hao, Q.; Zhang, C.; Zhang, Y.; Su, J. A Facile Construction of Porous g-C3N4/poly (3,4-ethylenedioxythiophene) Composite Modified Electrode for Ascorbic Acid Determination. J. Electrochem. Soc. 2018, 165, B118-B126. [CrossRef]

22. Yang, Y.; Hou, H.; Zou, G.; Shi, W.; Shuai, H.; Lib, J.; Ji, X. Electrochemical Exfoliation of Graphene-Like Two-Dimensional Nanomaterials. Nanoscale 2019, 11, 16-33. [CrossRef] [PubMed]

23. Wang, A.; Wang, C.; Fu, L.; Wong-Ng, W.; Lan, Y. Recent Advances of Graphitic Carbon Nitride-Based Structures and Applications in Catalyst, Sensing, Imaging, and LEDs. Nano-Micro Lett. 2017, 9, 1-21. [CrossRef]

24. Lin, J.; Pan, Z.; Wang, X. Photochemical Reduction of $\mathrm{CO}_{2}$ by Graphitic Carbon Nitride Polymers. ACS Sustain. Chem. Eng. 2014, 2, 353-358. [CrossRef]

25. Wang, R.; Li, H.; Zhang, L.; Zeng, Y.-J.; Lv, Z.; Yang, J.-Q.; Mao, J.-Y.; Wang, Z.; Zhou, Y.; Han, S.-T. Graphitic carbon nitride nanosheets for solution processed non-volatile memory devices. J. Mater. Chem. C 2019, 7, 10203-10210. [CrossRef]

26. Sanchez, S.; Fabregas, E.; Pumera, M. Electrochemical activation of carbon nanotube/polymer composites. Phys. Chem. Chem. Phys. 2009, 11, 182-186. [CrossRef]

27. Terse-Thakoor, T.; Komori, K.; Ramnani, P.; Lee, I.; Mulchandani, A. Electrochemically Functionalized Seamless Three-Dimensional Graphene-Carbon Nanotube Hybrid for Direct Electron Transfer of Glucose Oxidase and Bioelectrocatalysis. Langmuir 2015, 31, 13054-13061. [CrossRef]

28. Hashemi, P.; Dankoski, E.C.; Petrovic, J.; Keithley, R.B.; Wightman, R.M. Voltammetric Detection of 5-Hydroxytryptamine Release in the Rat Brain. Anal. Chem. 2009, 81, 9462-9471. [CrossRef]

29. Dinesh, B.; Veeramani, V.; Chen, S.-M.; Saraswathi, R. In Situ Electrochemical Synthesis of Reduced Graphene Oxide-Cobalt Oxide Nanocomposite Modified Electrode for Selective Sensing of Depression Biomarker in the Presence of Ascorbic Acid and Dopamine. J. Electroanal. Chem. 2017, 786, 169-176. [CrossRef]

30. Li, Y.; Ji, Y.; Ren, B.; Jia, L.; Ma, G.; Liu, X. Carboxyl-Functionalized Mesoporous Molecular Sieve/Colloidal Gold Modified Nano-Carbon Ionic Liquid Paste Electrode for Electrochemical Determination of Serotonin. Mater. Res. Bull. 2019, 109, 240-245. [CrossRef]

31. Ran, G.; Chen, X.; Xia, Y. Electrochemical Detection of Serotonin Based on a Poly(Bromocresol Green) Film and $\mathrm{Fe}_{3} \mathrm{O}_{4}$ Nanoparticles in a Chitosan Matrix. RSC Adv. 2017, 7, 1847-1851. [CrossRef]

32. Zhao, J.; Zhang, W.; Sherrell, P.; Razal, J.M.; Huang, X.-F.; Minett, A.I.; Chen, J. Carbon nanotube nanoweb-bioelectrode for highly selective dopamine sensing. ACS Appl. Mater. Interfaces 2012, 4, 44-48. [CrossRef] [PubMed]

33. Schmidt, A.C.; Wang, X.; Zhu, Y.; Sombers, L.A. Carbon nanotube yarn electrodes for enhanced detection of neurotransmitter dynamics in live brain tissue. ACS Nano 2013, 7, 7864-7873. [CrossRef]

Publisher's Note: MDPI stays neutral with regard to jurisdictional claims in published maps and institutional affiliations.

(C) 2020 by the authors. Licensee MDPI, Basel, Switzerland. This article is an open access article distributed under the terms and conditions of the Creative Commons Attribution (CC BY) license (http://creativecommons.org/licenses/by/4.0/). 